\title{
ARTIGOS \\ EMERGÊNCIA DE PLÂNTULAS DE CONYZA CANADENSIS E CONYZA BONARIENSIS EM SOLO COBERTO COM PALHA DA CULTURA DE MILHO
}

\author{
Yamashita $\mathrm{OM}^{*}$, Guimarães SC*
}

Resumo

Estudos relacionados com a biologia de plantas daninhas são importantes, pois contribuem para a adoção de estratégias de manejo racionais, aproveitando sistemas de rotação ou consorciação com culturas. Com o presente trabalho teve-se o objetivo de avaliar o efeito da presença de palha na emergência de plântulas de Conyza canadensis e C. bonariensis, espécies frequentemente relatadas como problemáticas em áreas de cultivo anual, perene, sistemas de semeadura direta e áreas de pousio. Para tanto, foi desenvolvido um experimento em esquema fatorial 2 x 5, sendo duas espécies e cinco quantidades de resíduos vegetais $\left(0,0 ; 1,5 ; 3,0 ; 4,5\right.$ e $6,0 \mathrm{Mg} \mathrm{ha}^{-1}$ de palha de milho). Foram avaliados o número de plântulas emersas semanalmente e a taxa de decomposição da palha no final do experimento. A emergência de plântula foi influenciada pela quantidade de palha, não havendo efeito principal de espécies de Conyza, e nem da sua interação com a quantidade de palha. A cobertura do solo com quantidades crescentes de palha de milho resultou em redução significativa na emergência de plântulas a partir de 1,5 $\mathrm{Mg} \mathrm{ha}^{-1}$. Pelos resultados apresentados, verificou-se a importância da manutenção de palhada de milho como cobertura do solo, que reduz significativamente a emergência de plântulas de Conyza, permitindo, assim, vantagem competitiva da cultura em relação à planta daninha.

Palavras-chave: Buva. Voadeira. Palha de milho. Cobertura do solo.

\footnotetext{
* Doutor em Agricultura Tropical pela Universidade Federal de Mato Grosso; Professor da Universidade do Estado de Mato Grosso; Avenida Perimetral Rogério Silva, 4930, Alta Floresta, Mato Grosso, Brasil; yama@unemat.br

** Doutor em Agronomia (Fitotecnia) pela Universidade Federal de Lavras; Professor da Universidade Federal de Mato Grosso, Cuiabá, Mato Grosso, Brasil; sheep@ufmt.br
} 


\title{
Conyza canadensis and Conyza bonariensis emergence in soil covered with maize straw
}

\author{
Abstract
}

Studies related to the biology of weeds are important, because they contribute to the adoption of rational crop strategies, taking advantage of rotation or consorciation systems. In the present work, the objective was to evaluate the effect of straw presence in the emergency of Conyza canadensis and C. bonariensis plants, species frequently seen as problems in areas of annual and perennial crops no-tillage systems and pousio areas. An experiment was developed in factorial scheme $2 \times 5$, i. e., two species and five amounts of vegetable residues $\left(0,0 ; 1,5 ; 3,0 ; 4,5\right.$ and $6,0 \mathrm{Mg} \mathrm{ha}^{-1}$ of maize straw). The number plant of emerged weekly and the tax of decomposition of the straw were evaluated at end of the experiment. The plant emergency was influenced by the amount of straw, with no main effect of species of Conyza nor of its interaction with the amount of straw. The soil covering with growing amounts of maize straw resulted in significant reduction in the plants emergency starting from $1,5 \mathrm{Mg} \mathrm{ha}^{-1}$. The results show the importance of haystack maintenance, as soil covering, which reduces the plants emergency significantly, allowing, thus, competitive advantage of the cultivation in relation to the weeds.

Keywords: Horseweed. Fleabane. Maize straw. Soil covering.

\section{INTRODUÇÃO}

O desenvolvimento das plantas está intimamente ligado aos fatores ambientais, e o clima e o solo constituem-se os elementos de maior interferência nesse desenvolvimento. A cobertura da área com resíduos vegetais afeta diretamente a incidência de luz, o teor de água, a temperatura e a fertilidade do solo e pode interferir no desenvolvimento das plantas, influenciando diversas etapas do seu ciclo de vida, inclusive a germinação das sementes. ${ }^{1,2,3}$ Esse é um dos processos mais importantes na organização e dinâmica das espécies vegetais, sendo muito sensível à presença de resíduos vegetais sobre o solo. ${ }^{4}$

Embora a profundidade em que as sementes estão localizadas no perfil do solo tenha implicação direta na emergência de muitas espécies daninhas, outro fator que pode influenciar diretamente na formação da comunidade infestante é a presença de palha na superfície do solo, como no caso de coberturas mortas presentes no momento da semeadura em áreas de semeadura direta. ${ }^{5}$

Esses resíduos vegetais alteram a umidade, a luminosidade e a temperatura do solo, que são tidas como as principais variáveis para o controle da dormência e da germinação das sementes. ${ }^{6,7,8} \mathrm{~A}$ presença de palha pode, também, prejudicar o desenvolvimento de plântulas, em razão da barreira física, provocando estiolamento e tornando-as mais suscetíveis a danos mecânicos ${ }^{4}$. Além desse efeito, compostos alelopáticos, com capacidade de inibir a germinação ou suprimir o crescimento das plântulas, podem ser liberados pela palha., ${ }^{9,10,2}$ 
Dessa maneira, a presença de resíduos vegetais sobre o solo pode interferir na dormência, germinação e mortalidade das sementes de plantas daninhas, gerando alterações profundas no banco de sementes da comunidade infestante. ${ }^{11,12}$ Entretanto, essas mudanças variam de acordo com a quantidade de palha e, principalmente, com a resposta da espécie daninha, que pode ser prejudicada pela presença desses resíduos.

Conyza canadensis e C. bonariensis são espécies daninhas cosmopolitas que têm sido relatadas como importantes infestantes de áreas de culturas perenes ${ }^{13}$ e lavouras anuais, ${ }^{14}$ incluindo as de semeadura direta. ${ }^{15,16,17}$

O conhecimento dos efeitos gerados pela presença de palha na emergência de C. canadensis e C. bonariensis permitirá a adoção de práticas culturais adequadas, aproveitando sistemas de rotação ou consorciação com culturas, no contexto do manejo integrado destas e de outras plantas daninhas.

Dessa forma, o objetivo com este trabalho foi determinar o efeito de resíduos vegetais da cultura de milho na emergência de C. canadensis e C. bonariensis.

\section{MATERIAL E MÉTODOS}

Para a investigação do efeito da palhada sobre a emergência de C. canadensis e C. bonariensis, foi realizado um experimento nas dependências da casa-de-vegetação da Universidade do Estado de Mato Grosso (Unemat), Alta Floresta, entre os meses de maio e junho de 2008.

As sementes de ambas as espécies de Conyza foram coletadas em outubro de 2007, de plantas espontâneas em áreas de cultivo na região de Alta Floresta, MT. Os capítulos foram colhidos manualmente, quando as sementes estavam prontas para dispersão pelo vento, ou seja, quando agitadas, ocorria o seu desprendimento da inflorescência. Após a colheita, foram deixadas para secar à sombra. Foi realizada uma seleção visual, descartando-se as sementes com evidência de danos ou as malformadas. As sementes selecionadas foram armazenadas em câmara refrigerada $\left(12,0 \pm 0,5^{\circ} \mathrm{C}\right)$ até seu uso.

Vasos de plástico com capacidade para 8,0 L de substrato (Tabela 1) foram utilizados para o experimento. Após a semeadura de cada tratamento, foi realizado umedecimento do solo por irrigação, procurando-se manter a umidade próxima de $80 \%$ da capacidade de campo. ${ }^{4}$ Cada tratamento teve quatro repetições, sendo utilizadas 50 sementes por parcela. 
Tabela 1 - Características físico-químicas do solo (profundidade de 0 a $20 \mathrm{~cm}$ ) utilizado no experimento ${ }^{\dagger}$

\begin{tabular}{|c|c|}
\hline Análise física-química & Valores \\
\hline pH em água & 7,10 \\
\hline Fósforo $\left(\mathrm{mg} \mathrm{DM}^{-3}\right)$ & 12,85 \\
\hline Potássio $\left(\mathrm{mg} \mathrm{DM}^{-3}\right)$ & 142,00 \\
\hline Cálcio $\left(\mathrm{cmol}_{\mathrm{c}} \mathrm{DM}^{-3}\right)$ & 12,00 \\
\hline Magnésio $\left(\mathrm{cmol}_{\mathrm{c}} \mathrm{dm}^{-3}\right)$ & 4,00 \\
\hline Alumínio $\left(\mathrm{cmol}_{\mathrm{c}}^{\mathrm{c}} \mathrm{dm}^{-3}\right)$ & 0,00 \\
\hline $\mathrm{H}^{+}+\mathrm{Al}^{+++}\left(\mathrm{cmol}_{\mathrm{c}} \mathrm{dm}^{-3}\right)$ & 2,39 \\
\hline Matéria orgânica $\left(\mathrm{g} \mathrm{dm}^{-3}\right)$ & 33,57 \\
\hline Saturação de bases (\%) & 77,26 \\
\hline Areia $\left(\mathrm{g} \mathrm{kg}^{-1}\right)$ & 595,2 \\
\hline Silte $\left(\mathrm{g} \mathrm{kg}^{-1}\right)$ & 107,2 \\
\hline Argila $\left(\mathrm{g} \mathrm{kg}^{-1}\right)$ & 297,6 \\
\hline
\end{tabular}

O experimento, dividido em duas etapas, foi organizado em esquema fatorial 2 x 5 ; sementes das duas espécies (C. canadensis e C. bonariensis) foram semeadas a $0,1 \mathrm{~cm}$ de profundidade e posteriormente cobertas com cinco quantidades de palhada $\left(0,0 ; 1,5 ; 3,0 ; 4,5\right.$ e $6,0 \mathrm{Mg} \mathrm{ha}^{-1}$ de palha de milho (cv Pioneer 3027)). Cada parcela recebeu a palha, que foi depositada em camada uniforme e em quantidade equivalente à preestabelecida para cada tratamento. A palha foi cortada em fragmentos menores, com tamanho inferior ou igual a 2,0 cm.

Na primeira etapa do experimento, foi avaliado o número de plântulas emersas em solo coberto com a palhada de milho, e, na segunda, a emergência destas após a remoção da palhada. $\mathrm{O}$ número de plântulas emersas foi contado aos 7, 14 e 21 dias. Nessa última data, foi considerado o momento em que se estabilizou o número de plantas emersas. Nessa última avaliação, retirou-se a palhada, que foi seca e pesada. Foram consideradas emersas em cada avaliação as plântulas visíveis com mais de $0,5 \mathrm{~cm}$ de parte aérea acima da camada de palha.

Com os valores de massa final (f) e inicial (i) da palha foram calculadas a quantidade de palha decomposta (D), pela fórmula $D=i-f$, e a taxa de decomposição (Td), pela fórmula $T d(\%)=100 d / i{ }^{18}$

Aos 28, 35 e 42 dias após a remoção da palhada, avaliou-se o número de plântulas emersas. As avaliações foram encerradas aos 42 dias em razão da estabilização do número de plântulas emersas.

De posse dos dados, realizou-se a comparação das médias de emergência de plântulas obtidas nas avaliações realizadas aos 21 e 42 dias pelo teste de Tukey a 5\% de probabilidade, sendo, ainda, ajustada uma equação quadrática para o fator quantidade de palhada na avaliação dos 42 dias. Também foi confeccionado um gráfico com as médias acumuladas de plântulas ao longo das avaliações.

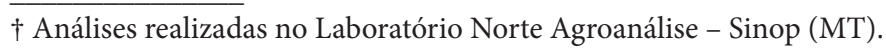




\section{RESULTADOS E DISCUSSÃO}

A emergência de plântula, tanto aos 21 quanto aos 42 dias, foi influenciada pela quantidade de palha $(\mathrm{p}<0,05)$, não havendo efeito principal de espécies de Conyza, nem da sua interação com a quantidade de palha ( $p>0,05)$ (Tabela 2$)$.

A cobertura do solo com quantidades crescentes de palha de milho resultou redução significativa na emergência de plântulas a partir de 1,5 $\mathrm{Mg} \mathrm{ha}^{-1}$, cujo percentual foi reduzido em $73 \mathrm{e} 69 \% \mathrm{em}$ relação à ausência de palha nas avaliações aos 21 e 42 dias, respectivamente. As demais quantidades permitiram a emergência de plântulas, entretanto, esses valores não foram superiores a 7,5\% na avaliação dos 21 dias e $13 \%$ aos 42 dias.

A palha pode ter promovido um impedimento físico ou, ainda, pode ter interferido de maneira indireta por meio da exudação de substâncias alelopáticas, sendo difícil diferenciar uma da outra em campo, já que ambas ocorrem de forma simultânea, ${ }^{19}$ pois sua presença na menor quantidade testada já foi suficiente para a redução significativa de plântulas emersas. De acordo com Teasdale e Mohler ${ }^{20}$ e Trezzi et al., ${ }^{21}$ os efeitos físicos da palha se devem ao sombreamento do solo, à barreira física para a emergência da planta daninha e à manutenção de temperaturas do solo mais baixas em relação ao solo descoberto.

Aos 42 dias, na presença de palha a partir de 3,0 $\mathrm{Mg} \mathrm{ha}^{-1}$, as médias de emergência (\%) foram semelhantes, indicando que, tanto para C. canadensis quanto C. bonariensis, a partir dessa quantidade de resíduo vegetal sobre o solo, há drástica redução na emergência dessas plantas daninhas e consequente estabelecimento. Assim, é esperado que em um sistema de produção que promova a produção de palha para cobertura do solo, a interferência imposta pelas duas espécies de Conyza seja menor comparativamente aos sistemas agrícolas que não utilizam cobertura com palha, mesmo que suas sementes permaneçam em profundidade de $0,1 \mathrm{~cm}$, como foi o caso do presente estudo. Oliveira, Alvarenga, Oliveira $\mathrm{e} \mathrm{Cruz}^{22}$ concluíram que à medida que se aumentava a quantidade de palha de milho (até $12 \mathrm{Mg} \mathrm{ha}^{-1}$ ), ocorria a redução na emergência de plantas daninhas na proporção de $4 \%$ para cada tonelada de palha adicionada no sistema. 
Tabela 2 - Emergência total (\%) de sementes de Conyza canadensis e C. bonariensis sob cobertura de quantidades crescentes de palha de milho. Alta Floresta, MT, 2014

\begin{tabular}{|c|c|c|}
\hline & \multicolumn{2}{|c|}{ Emergência (\%) } \\
\hline & 21 dias & 42 dias \\
\hline \multicolumn{3}{|l|}{ Espécie (E) } \\
\hline Conyza canadensis & 25,8 & 30,2 \\
\hline Conyza bonariensis & 27,8 & 32,0 \\
\hline Valor de F & $3,261^{\mathrm{ns}}$ & $0,978^{\text {ns }}$ \\
\hline \multicolumn{3}{|l|}{ Quantidade de palha (Q) } \\
\hline $0,0 \mathrm{Mg} \mathrm{ha}^{-1}$ & $97,5 \mathrm{a}$ & $98,5 \mathrm{a}$ \\
\hline $1,5 \mathrm{Mg} \mathrm{ha}^{-1}$ & $26,0 \mathrm{~b}$ & $30,8 \mathrm{~b}$ \\
\hline 3,0 $\mathrm{Mg} \mathrm{ha}^{-1}$ & $7,5 \quad c$ & $13,0 \quad c$ \\
\hline $4,5 \mathrm{Mg} \mathrm{ha}^{-1}$ & $2,3 \quad \mathrm{~d}$ & $7,8 \quad \mathrm{c}$ \\
\hline $6,0 \mathrm{Mg} \mathrm{ha}^{-1}$ & $0,8 \quad \mathrm{~d}$ & $5,5 \quad c$ \\
\hline Valor de F & $1084,716^{*}$ & $366,463^{*}$ \\
\hline \multicolumn{3}{|l|}{ Interação (E x Q) } \\
\hline Valor de F & $1,447^{\mathrm{ns}}$ & $1,725^{\mathrm{ns}}$ \\
\hline C.V. $(\%)$ & 13,07 & 18,57 \\
\hline
\end{tabular}

O tamanho da semente também é apontado como uma das razões para a reduzida emergência de plantas daninhas quando mantidas em condições de profundidade, pois como são pequenas, apresentam nos cotilédones reservas insuficientes para emergir a partir de grandes profundidades. ${ }^{23,24}$

A palha na superfície do solo funciona como filtro de luz, filtrando ou, até mesmo, impedindo a chegada de comprimentos de onda promotores da germinação às sementes. ${ }^{5}$ Dessa maneira, a manipulação do ambiente de luz pela produção de palhada em quantidade superior a $1,5 \mathrm{Mg} \mathrm{ha}^{-1}$ sob condições de campo é uma ferramenta potencial para o manejo de plantas daninhas fotoblásticas positivas, ou seja, aquelas que necessitam de estímulo luminoso para germinar.

Ambas as espécies estudadas são fotoblásticas positivas; assim, a germinação pode ser inibida pelo comprimento de luz vermelho-distante, por meio do controle da qualidade de luz exercido pelo fitocromo. ${ }^{25} \mathrm{~A}$ possível redução da incidência luminosa e a modificação da qualidade de luz que atingiu as sementes dessa espécie no solo promoveram redução na emergência. Diversas espécies de plantas daninhas têm sua dormência quebrada pela ação da luz quando esta é percebida pelos fotorreceptores, como o fitocromo. ${ }^{26,27}$ Estes, por sua vez, apresentam-se em duas formas: a forma inativa (Fv), com absorção máxima de comprimentos de onda de até $660 \mathrm{~nm}$, e a forma ativa (Fve), com absorção máxima de $730 \mathrm{~nm}$. Sob efeito luminoso ocorre a conversão de Fv para Fve, promovendo a quebra de dormência e posterior germinação das sementes. ${ }^{25}$

\footnotetext{
¥ ns não significativo pelo Teste $\mathrm{F}$.

* significativo a $5 \%$ de probabilidade, segundo o Teste $\mathrm{F}$.

Médias seguidas de mesma letra na coluna não diferem entre si pelo teste de Tukey a $5 \%$ de probabilidade.
} 
A quantidade de palha de milho decomposta foi diretamente proporcional à quantidade aplicada inicialmente, em cobertura (Tabela 3). Dessa maneira, quanto maior era a quantidade de palha utilizada na cobertura do tratamento, maior era a quantidade de material decomposto. Entretanto, quando se determinou a taxa de decomposição, esta seguiu um crescimento inversamente proporcional. Observou-se que maiores taxas de decomposição ocorreram quando foram aplicadas 1,5 e 3,0 $\mathrm{Mg} \mathrm{ha}^{-1}$, não havendo diferença do tratamento com 4,5 $\mathrm{Mg} \mathrm{ha}^{-1}$. Resultado semelhante foi obtido por Martins, Vellini, Martins e Souza, ${ }^{18}$ que observaram redução na taxa de decomposição de palha de cana-de-açúcar a partir de 4,0 $\mathrm{Mg} \mathrm{ha}^{-1}$.

Tabela 3 - Quantidade de palha de milho inicial, final e decomposta sobre a superfície do solo e taxa de decomposição. Média dos tratamentos utilizados ${ }^{\S}$

\begin{tabular}{cccc}
\hline \multicolumn{3}{c}{ Quantidade de palha $\left(\mathrm{Mg} \mathrm{ha}^{-1}\right)$} & \multirow{2}{*}{ Taxa de decomposição (\%) } \\
\hline Inicial & Final & Decomposta & $18,51 \mathrm{a}$ \\
1,50 & 1,22 & 0,28 & $18,56 \mathrm{a}$ \\
3,00 & 2,44 & 0,56 & $16,35 \mathrm{ab}$ \\
6,50 & 3,76 & 0,74 & $14,71 \mathrm{~b}$ \\
\hline
\end{tabular}

A persistência da palhada no solo é um indicador de qualidade de uma planta utilizada para produção de cobertura vegetal. Em condições de clima tropical, como foi o caso do presente estudo, em razão das condições de elevada temperatura e umidade, a decomposição de resíduos vegetais ocorre rapidamente, diminuindo sua persistência sobre o solo. ${ }^{28}$ Entretanto, como a palhada de milho apresenta maior relação $\mathrm{C} / \mathrm{N}$ que outras espécies utilizadas para produção de cobertura vegetal, como nabo forrageiro e azevém, a sua decomposição é mais lenta, ${ }^{29,30,31}$ permitindo vantagens como elevado rendimento de massa seca, controle da erosão do solo, aumento da infiltração de água e do conteúdo de carbono orgânico no solo, ciclagem de nutrientes e controle de plantas daninhas. ${ }^{32}$

Em experimento desenvolvido nos Estados Unidos, Main, Steckel, Hayes e Muller ${ }^{33}$ relataram que o resíduo do cultivo de milho da safra anterior reduziu a emergência de $C$. canadensis em comparação com resíduos de soja e algodão em sistema de semeadura direta. Foi observada uma redução de $77 \%$ na população dessa planta daninha em área com resíduos de milho em relação a áreas cujo cultivo anterior tinha sido a soja.

A remoção da cobertura aos 21 dias promoveu pouca emergência de plântulas, não havendo diferença entre as espécies (Figura 1). Pelo reduzido número de plântulas emersas, verificou-se que a manutenção de palha como cobertura do solo por 21 dias sobre as sementes favoreceu significativamente o controle de Conyza. Possivelmente, em condições de campo, na região em que a pesquisa foi desenvolvida, esse período seria suficiente para que a espécie de interesse econômico se desenvolvesse e promovesse o fechamento parcial da área, e, consequentemente, haveria maiores chances de competição com as plantas daninhas. Entretanto, vale ressaltar que em condições ambientais, a quantidade

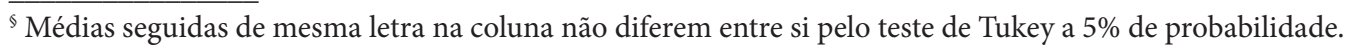


e a distribuição das sementes das plantas daninhas podem ser diferentes. Além disso, o tempo da degradação da palhada poderá ser maior ou menor, especialmente em razão de variáveis abióticas, como temperatura e umidade.

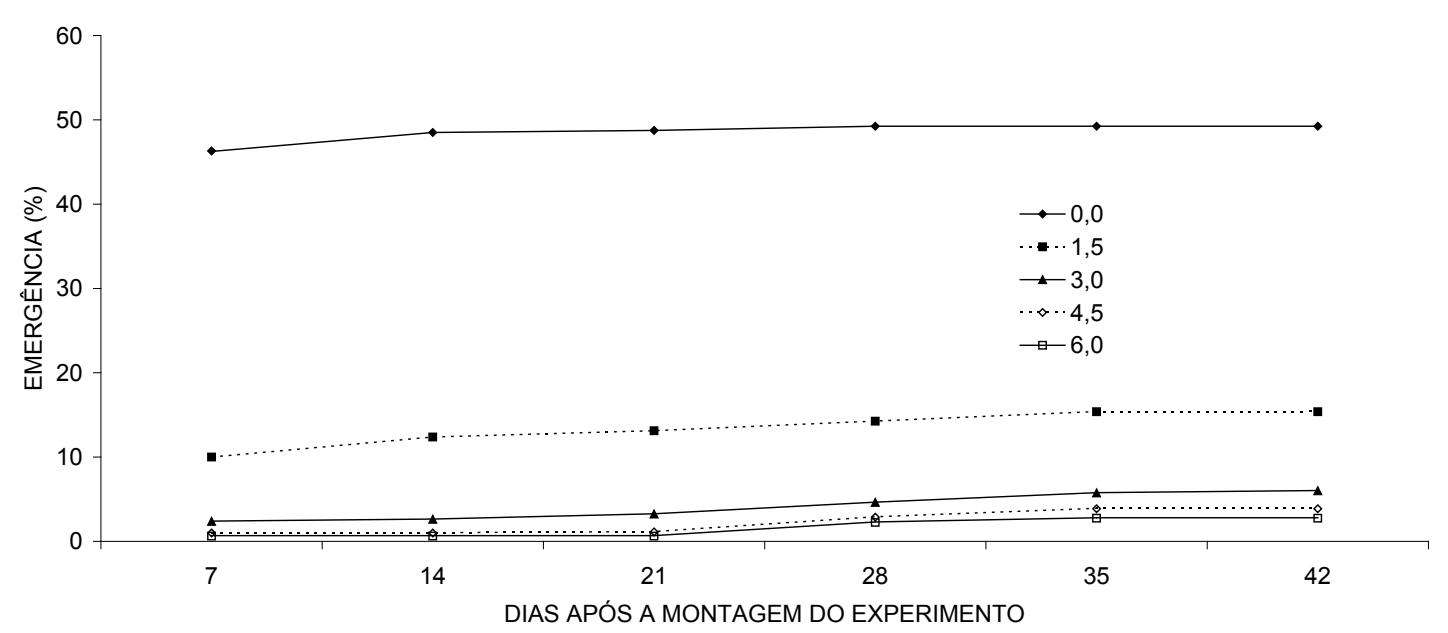

Figura 1 - Emergência de plântulas de Conyza com cobertura de palha de milho durante 42 dias. Aos 21 dias, foi retirada a palha, acompanhando-se a emergência das plântulas por mais 21 dias

Condições similares a essa, em sistema de semeadura direta, em que há maior concentração de sementes na superfície do solo, promovem um decréscimo do banco de sementes, em razão de diversos fatores, como indução à germinação, perda de viabilidade, deterioração ou predação e parasitismo pelo ataque de microrganismos e predadores. ${ }^{34}$ Nessas condições, o decréscimo dessa espécie será mais rápido ao longo do tempo.

Outras espécies como Brachiaria decumbens e Sida spinosa $a^{4}$ Sida rhombifolia ${ }^{18}$ também tiveram emergência de plântulas reduzida pela presença de palha de cana (a partir de 5,0 e 6,0 $\mathrm{Mg} \mathrm{ha}^{-1}$, respectivamente). Níveis de palha de aveia-preta na superfície do solo de 5,2 $\mathrm{Mg} \mathrm{ha}^{-1}$ aceleraram a mortalidade de sementes de Brachiaria plantaginea. ${ }^{3}$

Algumas variáveis biológicas podem ser beneficiadas com a presença de palhada no solo, pois esta cria condições para a instalação de densa e diversificada microbiocenose nessa camada superficial $^{35}$. Na composição dessa microbiocenose, há uma grande quantidade de microrganismos que podem consumir as sementes das plantas daninhas. De modo geral, esses microrganismos exercem importantes funções na deterioração e perda da viabilidade de diversos tipos de propágulos no solo. ${ }^{36}$ Também, a cobertura morta sobre o solo cria um ambiente seguro para predadores de sementes e plântulas, como roedores, insetos e outros pequenos animais. ${ }^{9}$ Além disso, a presença de palha pode promover o atraso na emergência das plantas daninhas, permitindo que a cultura se estabeleça, não resultando em perdas significativas no seu rendimento. ${ }^{37,38}$

A quiescência das sementes reflete a capacidade destas em germinar assim que o ambiente for favorável. Após os 21 dias iniciais, com a retirada da cobertura, não se observou aumento no número de plântulas de Conyza, provavelmente em decorrência das alterações fisiológicas e senescência das 
sementes. Theisen e $\operatorname{Vidal}^{10}$ também relataram esse efeito em sementes de Brachiaria plantaginea, sob 2,5 $\mathrm{Mg} \mathrm{ha}^{-1}$ de palha de aveia-preta.

Os resultados de emergência de plântula aos 42 dias, em razão da quantidade de palhada de milho, foram ajustados à regressão quadrática, nos quais 1,5; 3,0;4,5 e 6,0 $\mathrm{Mg} \mathrm{ha}^{-1}$ emergiram, respectivamente, 30,$8 ; 13,0 ; 7,8$ e 5,5\% das plântulas, constatando-se redução gradual no número de plântulas à medida que a quantidade de palha era aumentada (Figura 2).

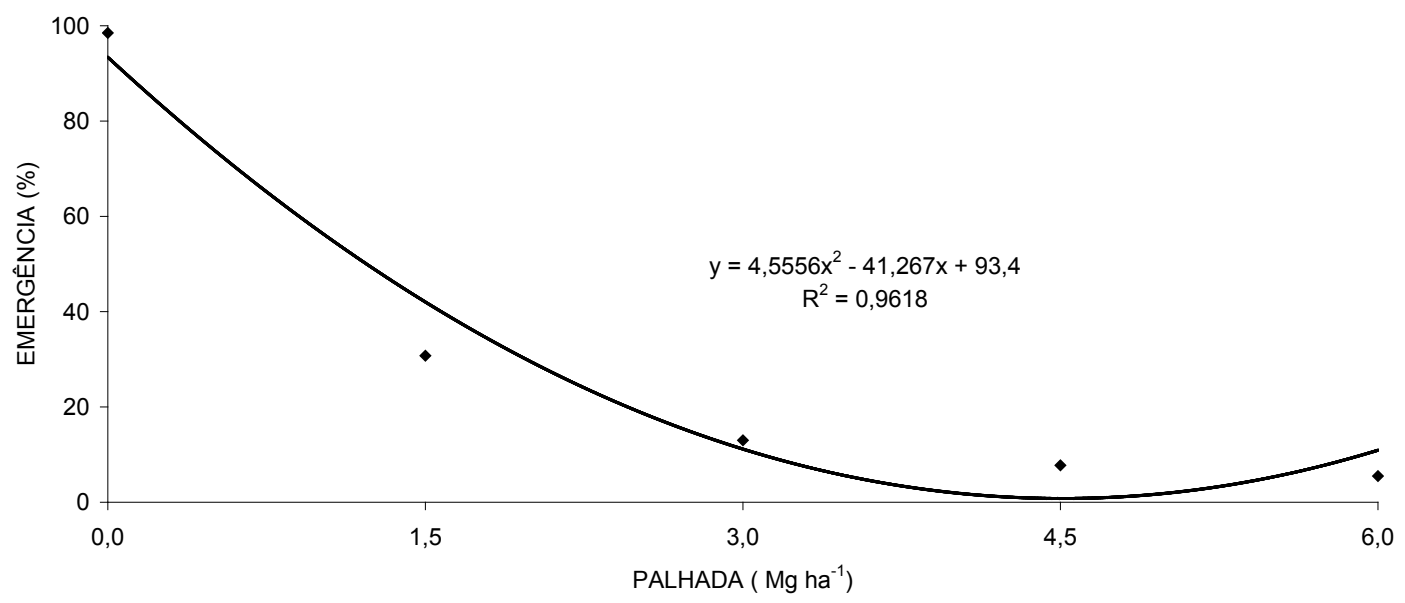

Figura 2 - Emergência de plântulas de Conyza, sob quantidades crescentes de palha de milho

A redução da quantidade e modificação da qualidade da luz que atinge as sementes em solos cobertos com palha na superfície também pode explicar a menor densidade de plantas daninhas em solos com cobertura. ${ }^{39,40}$

Pelos resultados foi possível verificar a importância da manutenção de palhada como cobertura do solo, o que reduziu significativamente a emergência de plântulas de Conyza, permitindo, assim, quando do estabelecimento da cultura no campo, vantagem competitiva em relação à planta daninha.

A utilização racional da cobertura vegetal no solo, formada a partir de resíduos deixados pela cultura anterior, pode permitir um tempo maior em que a cultura permaneça livre da interferência, podendo atrasar o momento de controle das plantas daninhas ou, até mesmo, em razão da quantidade de palha, suprimi-lo. ${ }^{33,40}$ Entretanto, as interações que ocorrem no ecossistema agrícola são muito específicas e dinâmicas, dependendo da quantidade de palha e, principalmente, da espécie daninha, que pode ser favorecida, ou não, pela cobertura vegetal. ${ }^{4}$

\section{CONCLUSÃO}

Nas condições em que foi desenvolvido o experimento, pode-se concluir que a presença de palhada de milho, a partir de 1,5 Mg ha-1, promove a redução significativa na emergência de plântulas 
de espécies de Conyza, que o número de plântulas de C. canadensis e C. bonariensis não é aumentado depois da retirada da cobertura após 42 dias.

\section{REFERÊNCIAS}

1. Fernandez-Quintanilla C. Studying the population dynamics of weeds. Weed Res. 1988; 28(6):4437.

2. Trezzi MM, Vidal RA. Potencial de utilização de cobertura vegetal de sorgo e milheto na supressão de plantas daninhas em condição de campo: II - efeitos da cobertura morta. Planta Daninha. 2004; 22(1):1-10.

3. Vidal RA, Theisen G. Efeito da cobertura do solo sobre a mortalidade de sementes de capim-marmelada em duas profundidades no solo. Planta Daninha. 1999; 17(3):339-44.

4. Correia NM, Durigan JC. Emergência de plantas daninhas em solo coberto com palha de cana-de-açúcar. Planta Daninha. 2004; 22(1):11-7.

5. Canossa RS, Oliveira Júnior RS, Constantin J, Biffe DF, Alonso DG, Franchini LHM. Profundidade de semeadura afetando a emergência de plântulas de Alternanthera tenella. Planta Daninha. 2007; 25(4):719-25.

6. Ball DA. Weed seedbank response to tillage, herbicides, and crop rotation sequence. Weed Sci. 1992; 40(4):654-9.

7. Clements DR, Benoit DL, Murphy SD, Swanton CJ. Tillage effects on weed seed return and seedbank composition. Weed Sci. 1996; 44(2):314-22.

8. Gomes Júnior FG, Christoffoleti PJ. Biologia e manejo de plantas daninhas em áreas de plantio direto. Planta Daninha. 2008; 26(4):789-98.

9. Alves PLCA, Pitelli RA. Manejo ecológico de plantas daninhas. Informe Agropecuário. 2001; 22(212):29-39.

10. Theisen G, Vidal RA. Viabilidade de sementes de papuã (Brachiaria plantaginea) e a cobertura do solo com palha. Cienc. Rural. 1999; 28(3):449-52.

11. Lorenzi H. Efeito da palha de cana no controle das plantas daninhas. In: Anais do $19^{\circ}$ Congresso brasileiro de herbicidas e plantas daninhas, 1993; Londrina. Londrina: Sociedade Brasileira da Ciência das Plantas Daninhas; 1993. p. 28-29.

12. Webster TM, Cardina J, White AD. Weed seed rain, soil seedbanks, and seedling recruitment in no-tillage crop rotations. Weed Sci. 2003; 51(4):569-75.

13. Kissmann KG, Groth D. Plantas infestantes e nocivas - Tomo II. 2. ed. São Paulo: BASF; 1999. 
14. Brown SM, Whitwell T. Influence of tillage on horseweed, Conyza canadensis. Weed Technol. 1988; 2(3):269-70.

15. Bhowmik PC, Bekech MM. Horseweed (Conyza canadensis) seed production, emergence, and distribution in no-tillage and conventional tillage corn (Zea mays). Agron. J. 1993; 1(1):67-71.

16. Bruce J, Kells J. Horseweed (Conyza canadensis) control in no-tillage soybeans (Glycine max) with preplant and preemergence herbicides. Weed Technol. 1990; 4(3):642-7.

17. Vargas L, Bianchi MA, Rizzardi MA, Agostinetto D, Dal Magro, T. Buva (Conyza bonariensis) resistente ao glyphosate na região Sul do Brasil. Planta Daninha. 2007; 25(3):573-8.

18. Martins D, Velini ED, Martins CC, Souza LS. Emergência em campo de dicotiledôneas infestantes em solo coberto com palha de cana-de-açúcar. Planta Daninha. 1999; 17(1):151-61.

19. Maciel CDG, Corrêa MR, Alves E, Negrisoli E, Velini ED, Rodrigues JD, et al. Influência do manejo da palhada de capim-braquiária (Brachiaria decumbens) sobre o desenvolvimento inicial de soja (Glycine max) e amendoim-bravo (Euphorbia heterophylla). Planta Daninha. 2003; 21(3):365-73.

20. Teasdale JR, Mohler CL. Light transmittance, soil temperature, and soil moisture under residue of hairy vetch and rye. Agron. J. 1993; 85(3):673-80.

21. Trezzi MM, Vidal RA, Mattei D, Silva HL, Carnieleto CE, Gustmann MS et al. Efeitos de resíduos da parte aérea de sorgo, milho e aveia na emergência e no desenvolvimento de plântulas de leiteiro (Euphorbia heterophylla) resistentes a inibidores da ALS. Planta Daninha. 2006; 24(3):443-50.

22. Oliveira MF, Alvarenga RC, Oliveira AC, Cruz JC. Efeito da palha e da mistura atrazine e motolachlor no controle de plantas daninhas na cultura do milho em sistema de plantio direto. Pesq. Agropec. Bras. 2001; 36(1):37-41.

23. Thomas WE, Burke IC, Spears JF, Wilcut JW. Influence of environmental factors on slender amaranth (Amaranthus viridis) germination. Weed Sci. 2006; 54(2):316-20.

24. Wilson Júnior DG, Burton MG, Spears JF, York AC. Doveweed (Murdannia nudiflora) germination and emergence as affected by temperature and seed burial depth. Weed Sci. 2006; 54(5):1000-3.

25. Zaidan LBP, Barbedo CJ. Quebra de dormência em sementes. In: Ferreira AG, Borghetti F. Germinação: do básico ao aplicado. Artmed: Porto Alegre; 2004.

26. Casal JJ, Sánchez RA. Phytochromes and seed germination. Seed Sci. Res. 1998; 8(3):317-29.

27. Foley ME. Seed dormancy: an update on terminology, physiological genetics, and quantitative trait loci regulating germinability. Weed Sci. 2001; 49(3):305-17.

28. Crusciol CAC, Moro E, Lima EV, Andreotti M. Taxas de decomposição e de liberação de macronutrientes da palhada de aveia preta em plantio direto. Bragantia. 2008; 67(2):481-9. 
29. Balbinot Júnior AA, Moraes A, Backes RL. Efeito de coberturas de inverno e sua época de manejo sobre a infestação de plantas daninhas na cultura de milho. Planta Daninha. 2007; 25(3):473-80.

30. Moraes PVD, Agostinetto D, Vignolo GK, Santos LS, Panozzo LE. Manejo de plantas de cobertura no controle de plantas daninhas na cultura do milho. Planta Daninha. 2009; 27(2):289-96.

31. Wisniewski C, Holtz GP. Decomposição da palhada e liberação de nitrogênio e fósforo numa rotação aveia-soja sob plantio direto. Pesq. Agropec. Bras. 1997; 32(11):1191-7.

32. Amado TJC, Mielniczuk J. Estimativa da adubação nitrogenada para o milho em sistemas de manejo e culturas de cobertura do solo. Rev. Bras. Ciênc. Solo. 2000; 24(1):179-89.

33. Main CL, Steckel LE, Hayes RM, Mueller TC. Biotic and abiotic factors influence horseweed emergence. Weed Sci. 2006; 54(6):1101-5.

34. Monquero PA, Christoffoleti PJ. Banco de sementes de plantas daninhas e herbicidas como fator de seleção. Bragantia. 2005; 64(2):203-9.

35. Correia NM, Durigan JC, Klink UP. Influência do tipo e da quantidade de resíduos vegetais na emergência de plantas daninhas. Planta Daninha. 2006; 24(2):245-53.

36. Matheis HASM. Efeitos de diferentes coberturas mortas obtidas a partir do manejo mecânico com roçadeira lateral na dinâmica populacional de plantas daninhas em citros [dissertação]. Piracicaba: Universidade de São Paulo; 2004.

37. Fleck NG, Rizzardi MA, Vidal RA, Merotto Júnior A, Agostinetto D, Balbinot Júnior AA. Período crítico para controle de Brachiaria plantaginea em função de épocas de semeadura da soja após dessecação da cobertura vegetal. Planta Daninha. 2002; 20(1):53-62.

38. Knezevic SZ, Weise SF, Swanton CJ. Interference of redroot pigweed (Amaranthus retroflexus) in corn (Zea mays). Weed Sci. 1994; 42(4):568-73.

39. Theisen G, Vidal RA, Fleck NG. Redução da infestação de Brachiaria plantaginea em soja pela cobertura do solo com palha de aveia-preta. Pesq. Agropec. Bras. 2000; 35(4):753-6.

40. Rizzardi MA, Silva LF, Vargas L. Controle de plantas daninhas em milho em função de quantidades de palha de nabo forrageiro. Planta Daninha. 2006; 24(2):263-70. 